STUDI

FRANCESI

\section{Studi Francesi}

Rivista quadrimestrale fondata da Franco Simone

192 (LXIV | III) | 2020

Texte et images entre Moyen Âge et Renaissance

(manuscrits et imprimés anciens)

\title{
CHRISTINE LE QUELLEC COTTIER, Le Terroriste noir de
}

\section{Tierno Monénembo}

\section{Roberto Ferraroni}

\section{(2) OpenEdition \\ 1 Journals}

\section{Edizione digitale}

URL: https://journals.openedition.org/studifrancesi/43101

DOI: 10.4000/studifrancesi.43101

ISSN: 2421-5856

\section{Editore}

Rosenberg \& Sellier

\section{Edizione cartacea}

Data di pubblicazione: 1 décembre 2020

Paginazione: 709-710

ISSN: 0039-2944

\section{Notizia bibliografica digitale}

Roberto Ferraroni, «CHRISTINE LE Quellec COTTIER, Le Terroriste noir de Tierno Monénembo», Studi Francesi [Online], 192 (LXIV | III) | 2020, online dal 01 mars 2021, consultato il 15 octobre 2022. URL: http:// journals.openedition.org/studifrancesi/43101; DOI: https://doi.org/10.4000/studifrancesi.43101

Questo documento è stato generato automaticamente il 15 octobre 2022.

\section{(c) (i) (9)}

Creative Commons - Attribuzione - Non commerciale - Non opere derivate 4.0 Internazionale - CC BYNC-ND 4.0

https://creativecommons.org/licenses/by-nc-nd/4.0/ 


\title{
CHRISTINE LE QUELLEC COTTIER, Le Terroriste noir de Tierno Monénembo
}

\author{
Roberto Ferraroni
}

\section{NOTIZIA}

CHRISTINE LE QUELLEC COTTIER, Le Terroriste noir de Tierno Monénembo, Gollion, Infolio, 2019, 129 pp.

1 La passione e l'interesse dell'autrice per l'argomento trattato emergono in maniera inequivocabile mentre si legge questo saggio. Specializzata in studi francofoni, Le Quellec Cottier approfondisce nell'opera la scrittura, e in particolare un romanzo, di Tierno Monénembo: Le Terroriste noir, pubblicato nel 2012. Si tratta di un testo che parla della vita di Addi Bâ, figura chiave della resistenza francese durante la seconda guerra mondiale, concentrandosi sui tre anni in cui, dopo essere arrivato in Francia dalla Guinea come fuciliere e esser stato fatto prigioniero, evade e si nasconde sui Vosgi, prima di essere nuovamente catturato, torturato e ucciso.

2 Nel primo capitolo, l'autrice guida brevemente il lettore per mano alla scoperta dei momenti più importanti della vita di Monénembo, dalla nascita in Guinea fino all'arrivo in Francia nel 1973, concentrandosi poi sulla sua attività di romanziere che inizia nel 1979 con la pubblicazione di Les Crapauds-brousse. Le Quellec Cottier mette in evidenza gli aspetti dell'opera dell'autore che fanno dei suoi romanzi esempi emblematici di «une écriture de l'exil», che caratterizza ogni suo scritto: in effetti dal momento del suo arrivo in Francia, lo scrittore non ha mai fatto ritorno nel suo paese natale.

Il secondo capitolo viene invece dedicato al contenuto del romanzo, che è descritto e analizzato approfonditamente e con estrema precisione, con continui riferimenti al testo e citazioni scelte per permettere al lettore di conoscere l'opera anche se non l'ha mai letta integralmente. Chi legge viene così a conoscenza dei tre anni vissuti da Addi Bâ sulle montagne, dove si era nascosto per sfuggire alla cattura, continuando ad operare nell'ombra per rendere forte la resistenza contro i tedeschi. Lo si conosce 
attraverso gli occhi dell'ormai anziana Germaine, che con lui e tante altre persone, ha vissuto quegli anni difficili. È un ritratto forse leggermente appannato dall'età della donna, ma che trasmette ugualmente al lettore il valore dell'uomo che lei sta disegnando con le sue parole.

4 Allontanandosi in parte dal contenuto del romanzo, con il terzo capitolo l'autrice vuole introdurre un argomento molto più ampio: quello della letteratura coloniale e postcoloniale, facendo notare come il romanzo dell'autore guineano si trovi a interfacciarsi e opporsi a questo tipo di letteratura. Se infatti da un lato viene evidenziato come all'epoca dell'arrivo di Addi in Francia «le "nègre" de l'époque coloniale est un homme-machine, un homme-marchandise corvéable à volonté, parce qu'associé à un monde du chaos dont la civilisation européenne se donne pour mission de le sortir» (p. 56) e in questo modo viene guardato da chi lo incontra senza conoscerlo, dall'altro lato Monénembo cerca di distruggere questo cliché, mettendo in evidenza le qualità di un uomo che è stato pronto a sacrificare persino la propria vita per la sua fede in un ideale, in una causa che avrebbe portato l'Europa fuori dalla barbarie in cui era sprofondata.

Il quarto capitolo si occupa invece principalmente del rapporto tra finzione e realtà nel romanzo. L'opera è sicuramente molto fedele ai fatti realmente accaduti, l'autore era ben documentato sull'argomento, quindi le pagine sono cronologicamente scandite con estrema precisione. Naturalmente non è possibile conoscere nel dettaglio la sua vita sulle montagne, così Le Quellec Cottier spiega come l'autore, introducendo il personaggio dell'anziana Germaine, abbia aggiunto alcuni tratti di finzione letteraria per adattare al meglio alla forma del romanzo la vita del protagonista, mantenendo però sempre ferma la verità storica degli eventi. Nell'ultimo capitolo, l'autrice vuole invece mettere in evidenza come «la créativité fictionnelle de Monénembo participe au nécessaire renouveau de l'histoire littéraire francophone africaine» (p. 105). L'autore guineano non si è mai dichiarato come aderente a una particolare corrente letteraria, al contrario si è sempre presentato come un «écrivain africain», ha sempre cercato di dar voce a coloro che sono generalmente sottomessi, alle voci più deboli della società, alle donne, alle minoranze politiche, ai suoi connazionali africani. In questa sua attitudine l'autore dimostra sicuramente grande coraggio, come conclude l'autrice del saggio, «Le Terroriste noir ne se résume pas à "un hommage aux oubliés de l'Histoire", ce qui a déjà été fait, mais il questionne les appartenances et les identités figées» (p. 117).

6 A conclusione del saggio vengono inserite alcune pagine di riferimenti biografici di Monénembo, in cui l'autrice mette in evidenza gli avvenimenti più importanti della sua vita, e una ricca bibliografia utilizzata per la stesura del saggio. L'opera è molto ben articolata, ricca di informazioni, scritta in uno stile chiaro e lineare. Le numerose citazioni, inserite nel testo in modo armonioso, sono di grande aiuto per conoscere più approfonditamente il romanzo di Monénembo, sia per chi ha avuto modo di leggerlo, sia per i lettori che non hanno avuto accesso al testo originale. 